\section{CHEMISTRY}

\section{Catalysis on a chip}

Three previously unknown catalytic reactions have been discovered using a chip-based array. The approach is similar to that by which researchers screen molecules for activity against drug targets.

John Hartwig and Daniel Robbins from the University of Illinois at Urbana-Champaign made an array of 345 potential catalysts by combining 15 metal-containing compounds with 23 organic fragments. To each of these candidates, they added 17 diverse small molecules as substrates for the catalytic reactions. Using mass spectrometry, the researchers checked whether any of the combinations had produced products that were heavier than their starting materials, indicating a successful reaction. Science 333, 1423-1427 (2011)

\section{MICROBIAL ECOLOGY}

\section{Reefs wrecked by shipwrecks}

Coral reefs near shipwrecks in the central Pacific Ocean probably become overwhelmed with dark microorganisms because of elevated levels of iron in the water.

Linda Kelly at San Diego State University in California and her colleagues studied three 'black reefs' (pictured, top) around the Line Islands, and compared them with nearby normal reefs (pictured,

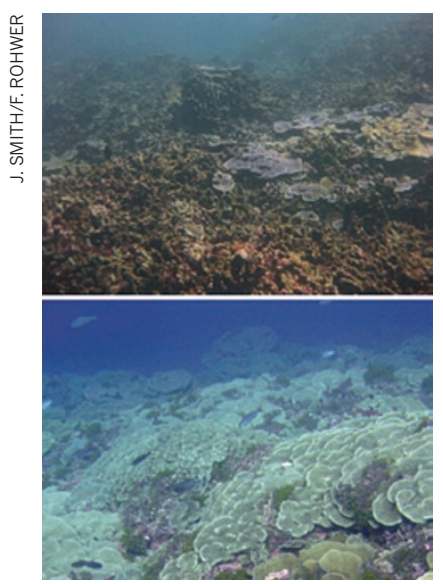

bottom). Live-coral coverage dropped from about $60 \%$ to less than $10 \%$ on the black reefs, and algal tissue from one of the sites contained high levels of iron, unusual for central Pacific waters. Sequencing the genomes of the reef's microbial populations revealed the presence of pathogens and genes involved in iron-related microbial virulence.

The team says that iron from the ships dissolves in the water, increasing the microbial growth that kills the coral. They call for the removal of shipwrecks from coral reefs. ISME J. http://dx.doi.org/ 10.1038/ismej.2011.114 (2011)

\section{ECOLOGY}

\section{Chemical warfare among cane toads}

Cane toads are one of the most destructive invasive species in Australia, but it is not just native animals that they harm. Michael Crossland and Richard Shine at the University of Sydney have found that the Rhinella marina tadpoles can cripple each other by releasing certain chemicals.

The duo placed cane-toad eggs in water with tadpoles of the same species. The tadpoles that grew from the eggs had a $41 \%$ lower body mass than those grown in 'clean' water. As they developed into toads, they had a $40 \%$ lower survival rate than unexposed tadpoles.

Native amphibians are not known to respond to canetoad pheromones, so they will probably not be affected by the chemical cues that impede development, the authors say. These chemicals could thus be used to control toad populations.

Biol. Lett. http://dx.doi.org/ 10.1098/rsbl.2011.0794 (2011)

\section{MICROSCOPY \\ Mobile imaging of the mouse brain}

Thanks to a fluorescence microscope small enough to be carried on the head of a moving mouse, researchers

COMMUNITY CHOICE

The most viewed papers in science

\title{
A long history of Icelandic ash
}

HIGHLY READ
on geology.
gsapubs.org
in August

There could be a high risk of extensive ash clouds from Icelandic volcanoes wafting across Europe soon, causing disruption similar to that which occurred as a result of the eruption of

Eyjafjallajökull on 20 March last year.

Graeme Swindles at the University of Leeds, UK, and his colleagues found traces of volcanic ash from Iceland in peats and lake sediments across northern Europe. These, along with historical records, suggest that ash clouds from Icelandic eruptions have, on average, reached northern Europe every 56 years or so over the past 1,000 years. The team estimates that there is at least a $16 \%$ likelihood of this happening in any given ten-year period. Geology 39, 887-890 (2011)

at Stanford University in California have unveiled details of how the brain controls blood flow and motor activity.

The microscope, developed by Mark Schnitzer and his colleagues, weighs just 1.9 grams, has a volume of 2.4 cubic centimetres and is made from mass-produced components. The researchers used the device to monitor the brains of three freely moving mice. The results revealed, for example, that capillaries separated by only tens of micrometres can behave differently during movement, indicating that the brain has finer control of blood flow than had been realized.

The authors say that their microscope, which has a lower resolution than conventional fluorescent microscopes, can be cheaply mass produced.

Nature Meth. http://dx.doi. org/10.1038/nmeth.1694 (2011)

\section{PHYSIOLOGY \\ Biological clocks work in the dark}

Animals match their biological rhythms to the day-night cycle thanks to their circadian

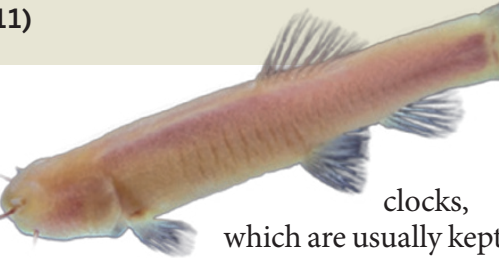
on time using cues from light. But do organisms that live in perpetual darkness, such as the blind cavefish (Phreatichthys andruzzii; pictured), have such clocks? Cristiano Bertolucci at the University of Ferrara in Italy and his colleagues show that they do. However, the clock's oscillations are set by feeding times, not light, and cycle every 47 hours, rather than every 24.

The team compared zebrafish (Danio rerio), which have light-entrained clocks, with the cavefish and found that two light-sensitive proteins, melanopsin and TMT-opsin, were present in both fish but mutated in the cavefish. The zebrafish versions of the proteins, when expressed in cavefish cells, restored the cells' sensitivity to light - proving that the proteins function as the photoreceptors that coordinate fish circadian clocks.

PLoS Biol. 9, e1001142 (2011)

\section{$\rightarrow$ NATURE,COM}

For the latest research published by Naturevisit:

www.nature.com/latestresearch 